\title{
HUMAN RELIABILITY AT SHIP SAFETY CONSIDERATION
}

\section{NIEZAWODNOŚĆ CZŁOWIEKA W ASPEKCIE BEZPIECZEŃSTWA STATKU}

\author{
Leszek Smolarek \\ Gdynia Maritime University, Faculty of Navigation \\ Morska 81-87, Gdynia, Poland \\ Akademia Morska w Gdyni, Wydzial Nawigacji \\ ul. Morska 81-87, Gdynia
}

\begin{abstract}
Human reliability is one of main factors which influence safety at maritime transport. The tendency of decreasing the crew number can growth the human fatigue factor. So it's necessary to analyze human fatigue and human reliability for seaman as factors which can cause the ship catastrophe.
\end{abstract}

Keywords: human error, human factors, reliability, ship safety

Streszczenie: Niezawodność człowieka jest jednym z istotnych czynników wpływających na bezpieczeństwo $\mathrm{w}$ transporcie morskim. Występujące ostatnie tendencje do zmniejszania liczebności załóg, będące efektem stosowania nowoczesnych coraz bardziej zautomatyzowanych systemów w siłowniach jak i na pokładzie, mogą prowadzić do nadmiernego obciążenie marynarzy zarówno fizycznego jak i psychicznego. Dlatego niezbędnym jest analiza wpływu niezawodności marynarzy na szanse popełnienia błędu przez człowieka na statku mogącego prowadzić do awarii lub katastrofy.

Słowa kluczowe: błąd ludzki, czynnik ludzki, niezawodność, bezpieczeństwo statku 


\section{HUMAN RELIABILITY AT SHIP SAFETY CONSIDERATION}

\section{Introduction}

The term "human reliability" is defined as the probability that a person (seaman) will correctly performs system-required activity during a watch time period without performing any extraneous activity that can cause the hazard of a ship.

Within the context of this paper human errors are defined as errors made by humans in ship operation which leads to an immediate dangerous situation or accident.

The Human Reliability Analysis starts at early 1960s but most methods were developed at $1980 \mathrm{~s}$ as an effect of nuclear power plant accident at There Mile Island. At the traditional approach the Human Error Probability (HEP) is determined at first.

The characterization of human failure modes is very simple, in terms of "error of omission" and "errors of commission".

Human actions at ship is strongly correlated with environment parameters type of ship and social conditions so its necessary to take into account the influence of possible Performance Shaping Factors (PSF) such as task characteristics, aspects of the physical environment, work time characteristics, etc.

This influence can be expressed as a numerical factor that is used to modify the basic HEP and the resulting formula is shown below:

$$
P_{E A}=H E P_{E A} \cdot \sum_{k=1}^{N} P S F_{k} \cdot W_{k}+C
$$

Two fundamental assumptions are:

- the probability of failure can be determined for specific types of action independently of any context;

- the various performance conditions such as interface quality, stress, level of training, task complexity, etc. are independent of oneself, (1).

Neither of these assumptions is reasonable, and either alone constitutes a grave deficiency of the approach. 
Niezawodność człowieka w aspekcie bezpieczeństwa ....

Human error plays a significant role in ship accident causation, (fig.1).

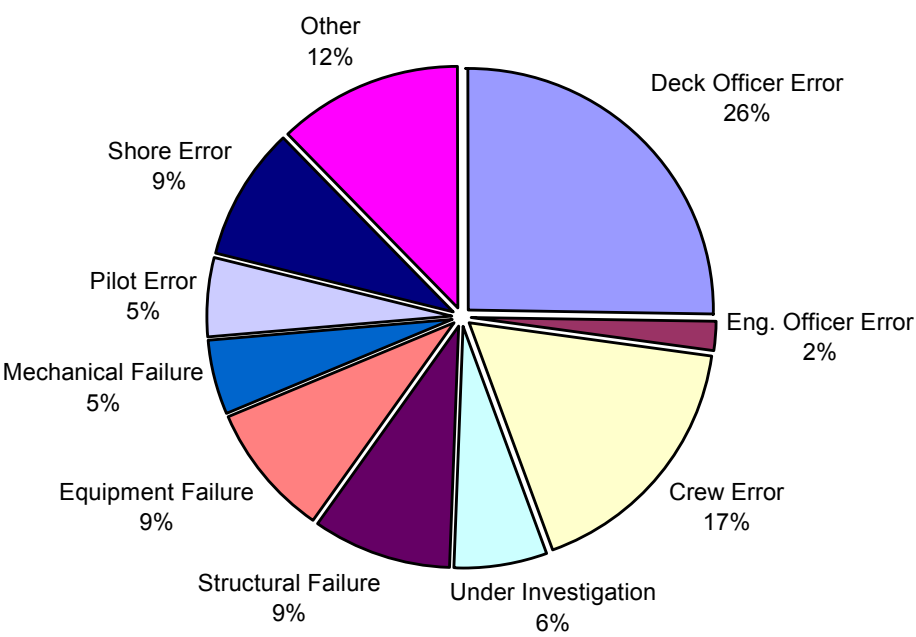

Fig.1: Percentage of the principal causes of ship accidents, [5]

Making a mistake by the man shipboard can result:

- of not carrying the required activity out with the procedure,

- of wrong making the required activity with the procedure,

- of carrying the activity at variance with the procedure out.

The competence and motivation of people responsible for the operation of safety-critical systems is the first line of defense against loss of life and property. The circumstances and influences that cause people to embrace or ignore best practice in safety-critical ship operations or operational procedures invite detailed analysis, (fig.2).

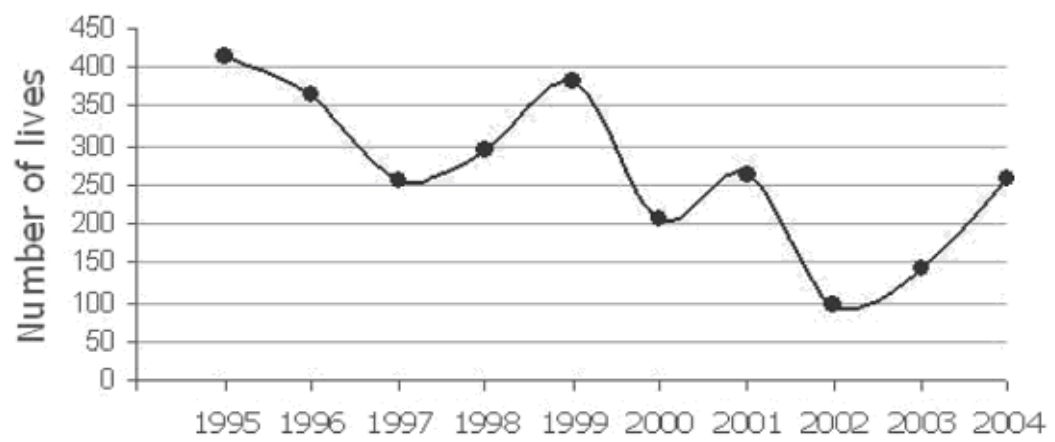

Fig.2. Live lost International Cargo Ships, from Managing Risk DNV ${ }^{1}$.

${ }^{1}$ www.dnv.com 
In the presence of individuals that do not value safety, the probability that systemic defects will be injected into operational procedures is high.

\section{Human fatigue modeling}

Examples of current fatigue models that may be suitable for inclusion in the seaman fatigue modeling structure, the models described herein address cognitive fatigue [2].

\section{The Two-Process Model}

Developed initially for the sleep-research field, Achermann's two-process model resides at the basis of many models that address the regulation of fatigue and performance. Based on electroencephalographic slow-wave data collected during non-REM sleep, the model includes a linear interaction of homeostatic and circadian processes and an exponential sleep-inertia component. In 2003, the software associated with this model did not have a standard interface and could not be updated in real-time.

\section{Sleep/Wake Predictor Model}

Akerstedt developed this model using empirical subjective alertness data from altered sleep/wake patterns. It assumes an eight-hour sleep period to begin, an exponential fall in alertness during wakefulness, followed by an exponential rise in alertness during sleep. It uses circadian rhythm peak alertness at 4:48 PM, and an exponential sleep-inertia factor. The model was developed for sleep researchers, companies demanding irregular work schedules, and organizations governing safe work-hour regulations. The software allows real-time updates and has screen outputs that include sleep latency, duration and bedtime, as well as alertness and performance curves.

\section{System for Aircrew Fatigue Evaluation (SAFE)}

Developed primarily for aviation operation applications, the SAFE model grew out of laboratory experiments and was fine tuned using long-haul flight operational data. The model is a "combination of sinusoidal component in time of day and a cubic trend in time since sleep." Currently being used by the UK Civil Aviation Authority, the interface displays results graphically in two-week time frames, alertness levels are colorcoded, and the existing version of the model (in 2003) did not accept realtime updates.

\section{Interactive Neurobehavioral Model}

This model uses a combination of circadian, homeostatic, and sleep-inertia components to estimate neurobehavioral performance. It assumes initial conditions of eight hours of sleep in darkness and 16 hours of wakefulness in 150 lux illumination. Validation studies with human subjects include 
varying light patterns, jet lag, sleep deprivation, and non-24 hour schedules. The PC-compatible software allows inputs of light levels and sleep/wake times, while the output graphs performance, alertness, and minimum core body temperature. This model is used by NASA and DoD researchers.

\section{SAIC Human Performance Cognitive Model (HPCM)}

This holistic model considers fatigue as only one of several stressors that can have a limiting influence on human performance in information operations (e .g. decision-making, target selection, situation analysis, mission analysis, and communication). The HPCM can produce as outputs minute-to-minute estimates of human effectiveness (as a percentage of maximum), time delay, and decision-making styles (called types by the authors). The model has been implemented in Windows-compatible simulation software, which has a user interface consisting of input and parameter adjustment screens and a run-time output screen, whose minuteto-minute estimates are entered into an Excel spreadsheet. The HPCM assumes an underlying naturalistic decision-making process, as stipulated by Klein and colleagues $[3,4]$. In addition to the influences of sleep-deprivation and fatigue on performance, the model accounts for the stressors of 1) time pressure ( $i$.e. having less than optimal time to perform a task), 2) personality (aggressive/risk tolerant vs. non-aggressive/risk averse), and 3) threats of failure and confidence builders (e .g. hearing that your forces achieved a goal). The model also accounts for significant modulators of stress, including training, experience, and intelligence.

The sleep-deprivation and fatigue stressors are the most interesting factors.

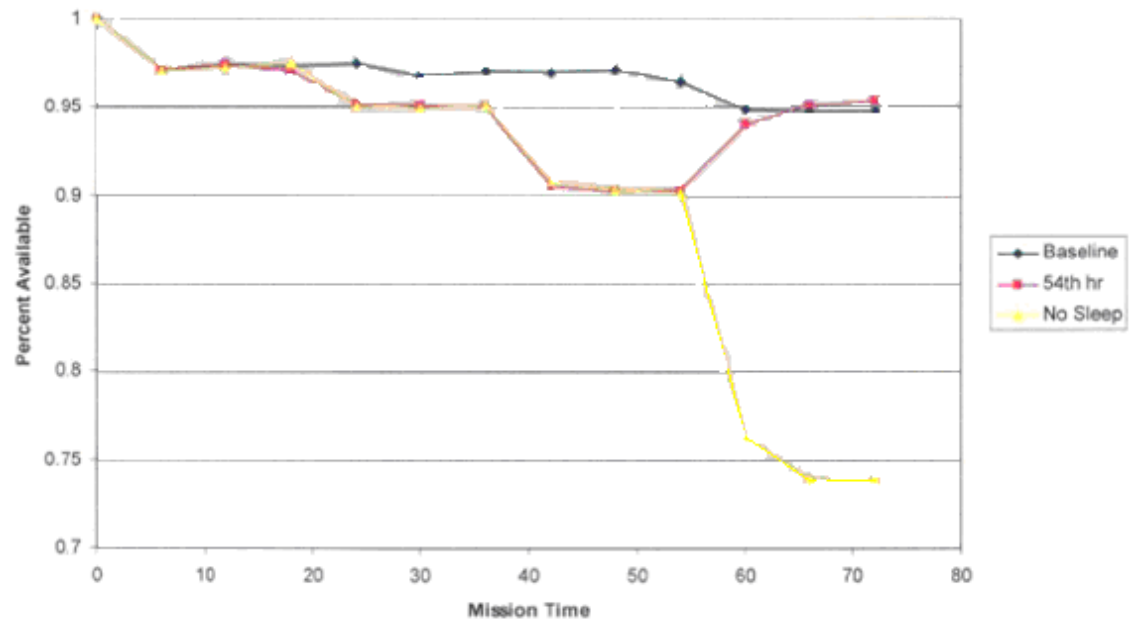

Fig.3. Operational availability under sleep deprivation [2] 
Probability of operator error is given by formula [3]

$$
Q\left(\frac{t}{T_{m}}\right)=\exp \left\{-\left(\frac{t-a_{1} \cdot T_{m}}{a_{2} \cdot T_{m}}\right)^{a_{3}}\right\}
$$

where

- $a_{1}, a_{2}, a_{3}$ are parameters connected with factors such as skills, knowledge, regulations;

- $T_{m}$ is an average time for analyzed operation;

- $t$ is time which operator has for this operation.

The fatigue model should consist of three functions:

- first which describes attentional lapses,

- second which describes the slowing of optimal response time,

- third which describes routine hurry lapses.

First two functions are causes by human fatigue

Example of adjustment to the night schedule of the USS John C. Stennis Crewmembers ${ }^{2}$

Table 1. Reported Adjustment Probability to Schedule by Gender, [1]

\begin{tabular}{|l|c|c|c|}
\hline Completely adjusted & Male & Female & Total \\
\hline No & 0,409091 & 0,666667 & 0,464286 \\
\hline Yes & 0,590909 & 0,333333 & 0,535714 \\
\hline
\end{tabular}

\section{Human error and ship safety}

Ship operations are safety critical in many respects, and the safety of marine transport is based upon a blend of safety management, navigation rules, technical safety equipment and human reliability.

Errors of ${ }^{3}$ :

- Omission

$\circ$ Omit actions / sub-goals

- Commission

○ Substitute actions / sub-goals

\footnotetext{
${ }^{2}$ http://www.nps.navy.mil/orfacpag/resumePages/projects/

${ }^{3}$ Michael Harrisom, Human error analysis and reliability assessment, DIRC
} 
- Carry out action incorrectly

- Insert extraneous action

- Sequence

○ Actions in wrong order

- Repetition

- Actions repeated unnecessarily

- Qualitative error

- Too much / too little

- Time error

○ Too early / too late / too long

Each of these cases needs to take under consideration essentiality of decision taken for ship safety, under note by person who does it (sailor, officer on bridge). For risk estimation the following model can be employ

$P($ accident $)=1-\prod_{k \in K}\left[1-P\left(B D_{k}\right) P\left(I D_{k}\right]^{r_{k}}\right.$

where

$\mathrm{BD}_{\mathrm{k}}$ - human error,

$\mathrm{ID}_{\mathrm{k}}$ - error relevance,

$\mathrm{r}_{\mathrm{k}}-\mathrm{k}$-th error rang.

$\mathrm{K}-$ set of possible human errors.

Table 2. Failure probabilities on account of human error, [4].

\begin{tabular}{|l|l|}
\hline \multicolumn{1}{|c|}{ Accident } & \multicolumn{1}{|c|}{ Confidence interwal $\mathbf{6 8 \%}$} \\
\hline Ships collision to rate opposite & {$\left[1,39 \cdot 10^{-5} ; 1,71 \cdot 10^{-4}\right]$} \\
\hline $\begin{array}{l}\text { Ships collision to rate with } \mathrm{z} \\
\text { overtaking }\end{array}$ & {$\left[3,03 \cdot 10^{-5} ; 3,92 \cdot 10^{-3}\right]$} \\
\hline $\begin{array}{l}\text { Ships collision to rate to rate } \\
\text { cross yourselves }\end{array}$ & {$\left[8,5 \cdot 10^{-5} ; 9,82 \cdot 10^{-3}\right]$} \\
\hline Entry to shoal & {$\left[6,07 \cdot 10^{-5} ; 4,11 \cdot 10^{-3}\right]$} \\
\hline Percussion ex object regular & {$\left[5,16 \cdot 10^{-5} ; 6,69 \cdot 10^{-3}\right]$} \\
\hline
\end{tabular}


Table 3. Critical Entity Table for the Noordam Accident ${ }^{4}$

\begin{tabular}{|c|c|c|c|}
\hline \multicolumn{2}{|c|}{ Physical Locations } & Roles & $\begin{array}{c}\text { Information/Control } \\
\text { Systems }\end{array}$ \\
\hline \multicolumn{2}{|c|}{ captain_veniamis } & lookout & arpa_radar \\
\hline \multicolumn{2}{|c|}{ pacific trident } & chief officer & visual \\
\hline \multicolumn{2}{|c|}{ mount_ymitos } & first officer & binoculars \\
\hline \multicolumn{2}{|c|}{ noordam } & third officer & - \\
\hline \multicolumn{2}{|l|}{-} & fourth officer & - \\
\hline \multicolumn{2}{|l|}{-} & watch officer & - \\
\hline Operators & \multicolumn{2}{|c|}{ Speech Acts } & Tasks \\
\hline pilot station & \multicolumn{2}{|c|}{ inbound pacific trident } & navigation_radar_check \\
\hline engine room & \multicolumn{2}{|c|}{ inbound_captain_veniamis } & collision_radar_check \\
\hline smit & \multicolumn{2}{|c|}{ outbound_mount_ymitos } & correlate_radar_targets \\
\hline salyo & \multicolumn{2}{|c|}{ curse } & declare_end_of_sea_voyage \\
\hline broekhoven & \multicolumn{2}{|c|}{ take bearing on lights } & fix_vessel_position \\
\hline veldhoen & \multicolumn{2}{|c|}{ lights moving right } & complete $\log$ \\
\hline kuiper & \multicolumn{2}{|c|}{ officer_change } & notify_engine_room \\
\hline- & \multicolumn{2}{|c|}{-} & end_of_sea_voyage \\
\hline- & \multicolumn{2}{|r|}{-} & left_full_rudder \\
\hline
\end{tabular}

\section{Conclusions}

For more sophisticated cognitive modeling is necessary to model numerous human failure modes (e .g. lack of sleep, training, stress) or represent complex interdependencies between social parameters, work and rest schedule, ship route, ship technical and exploitations parameters. An alternative to representing the seaman as an element of a ship system is to represent him as a subsystem in and of itself. It means that the seaman should be modeled autonomously. Modeling the seaman as an independent system would allow for more detailed treatment of sleep, activity, and sleepreplenishment functions.

\section{Bibliography}

1. Miller N. L., Nguyen J., USN Working the Nightshift on the USS John C. Stennis: Implications for Enhancing Warfighter

\footnotetext{
${ }^{4}$ http://www.dcs.gla.ac.uk/research/gaag">Glasgow Accident Analysis Group
} 
Effectiveness,

http://www.nps.navy.mil/orfacpag/resumePages/projects/

2. Craig R. Lawton, Dwight. P. Miller, James E . Campbell Human Performance Modeling for System of Systems Analytics: Soldier Fatigue, SAND REPORT, SAND2005-6569, Unlimited Release, Printed October 2005,

3. L. Smolarek \& J. Soliwoda, Human Fatigue Model at Maritime Transport, Proceedings of ESREL 2008 Conference (to appear).

4. Gucma L. Modelowanie ryzyka zderzenia jednostek pływających z konstrukcjami portowymi i pełnomorskimi, Studia nr.44 Akademia Morska w Szczecinie, Szczecin 2005.

5. Soares C.G.; Teixeira A.P. 2001, Risk assessment in maritime transportation, Reliability Engineering and System Safety, Volume 74, Number 3, December 2001 , pp. 299-309(11) Elsevier 


\section{NIEZAWODNOŚĆ CZLOWIEKA W ASPEKCIE BEZPIECZEŃSTWA STATKU}

\section{Wstęp}

Niezawodność człowieka jest definiowana jako prawdopodobieństwo, że człowiek (marynarz) w czasie wachty będzie prawidłowo wykonywał wszelkie przewidywane operacje i czynności powstrzymując się od innej nie planowanej działalności mogącej stanowić zagrożenie dla statku i załogi.

W przedstawionym artykule błędem ludzkim nazywane są błędy popełnione przez człowieka $\mathrm{w}$ czasie pracy na statku bezpośrednio prowadzące do sytuacji zagrożenia albo wypadku.

Badania niezawodności człowieka rozpoczęto na początku lat sześćdziesiątych (1960 -) ale główny rozwój nastąpił w latach osiemdziesiątych jako efekt pośredni wypadku w elektrowni atomowej There Mile Island. W klasycznym podejściu najpierw określono prawdopodobieństwo błędu ludzkiego (Human Error Probability - HEP).

Prawdopodobieństwo błędu (HEP) jest określane w terminach "błędy opuszczenia " i "błędy popełnienia". Działalność człowieka na statku podlega silnym wpływom środowiska zewnętrznego, zależy też od parametrów techniczno eksploatacyjnych statku a także czynników społeczno-socjalnych, dlatego należy rozpatrywać czynniki określające aktywność człowieka Performance Shaping Factor (PSF) takie jak stan fizyczny czas pracy itp. Wpływ PSF może być wyrażany jak liczbowy czynnik używany do modyfikacji HEP według wzoru:

$$
P_{E A}=H E P_{E A} \cdot \sum_{k=1}^{N} P S F_{k} \cdot W_{k}+C
$$

Podstawowymi założeniami są:

prawdopodobieństwo niepowodzenia może być określane dla specjalnych typów czynności niezależnie od wszelkiego kontekstu; rozmaite warunki dla wykonanie prawidłowo operacji czy też podjęcia decyzji w rodzaju poziom stresu, poziom wyszkolenia, komplikacja zadania, i tak dalej są niezależny (1). 
Żadne $\mathrm{z}$ tych założeń nie jest $\mathrm{w}$ pełni prawdziwe i tworzy to poważny deficyt tego typu podejścia.

Ludzki błąd gra znaczącą rolę w wystapieniu wypadku w transporcie morskim.

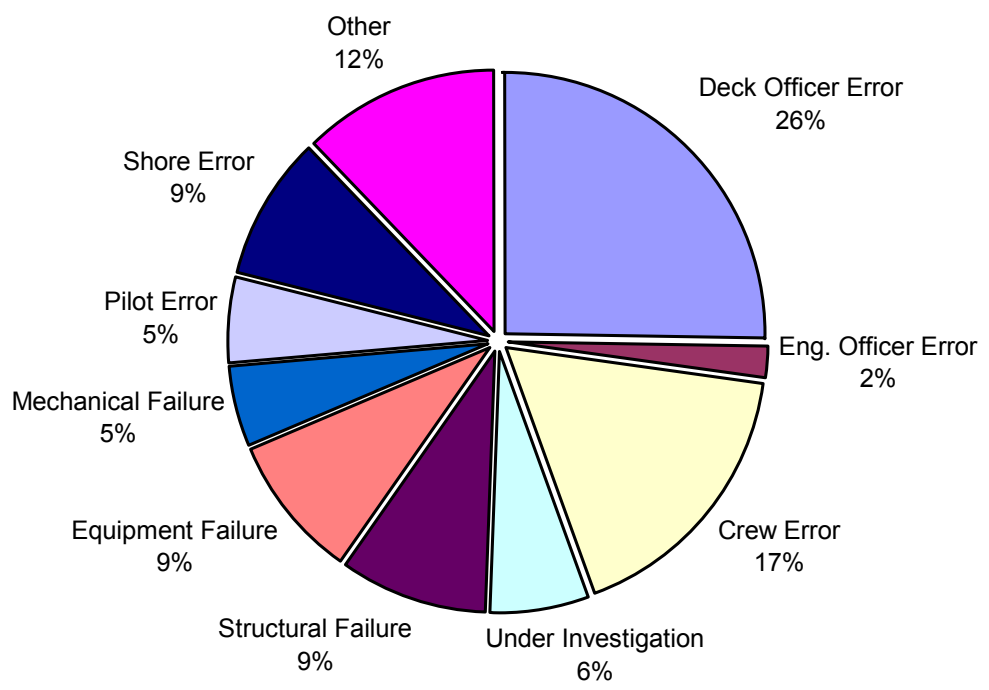

Rys.1 Przyczyny wypadków w transporcie morskim, [Błąd! Nie można odnaleźć źródła odwolania.]

Przyczynami błędów ludzkich są:

- nie wykonania wymaganych procedurą operacji,

- nieprawidłowego wykonania wymaganych procedurą operacji,

- wykonania czynności niezgodnych z procedurą operacji.

Kompetencja i motywacja człowieka odpowiedzialnego za działania krytyczne dla bezpieczeństwa systemy są na pierwszej linią obrony $\mathrm{w}$ zabezpieczaniu życia i mienia. Okoliczności i wpływy powodujące ignorowanie prawideł postępowania przy operacjach i decyzjach wpływających na bezpieczeństwo statku i załogi wymagają dokładnej analizy. 


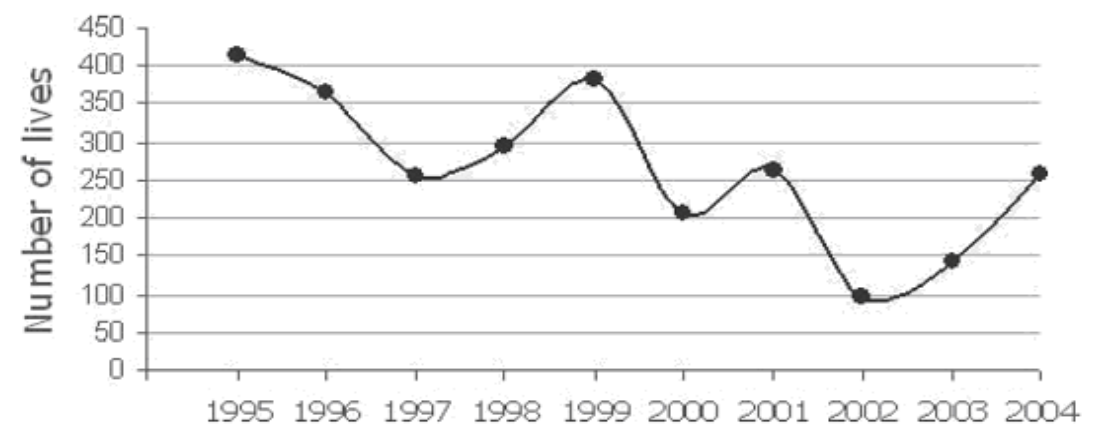

Rys.2. Wypadki śmiertelne w transporcie morskim, na podstawie Managing Risk DNV 5 .

W przypadku członków załóg, które nie przywiązują zbytniej wagi do bezpieczeństwa, prawdopodobieństwo, że błędy systematyczne będą stępować w procedurach eksploatacyjnych jest wysokie.

\section{Modelowanie zmęczenia czlowieka}

Wybrane przykłady modeli zmęczenia człowieka, który można stosować w transporcie morskim, modele poznawcze przedstawione poniżej dotyczą badania zmęczenia, [6].

\section{Model dwuprocesowy}

Model ten powstał początkowo dla badań nad snem, dwu procesowy model Achermannsa jest podstawą wielu modeli opisujących związki zmęczenia $i$ działania. Model opracowano wykorzystując dane zebrane w oparciu o encefalogramy wykonane $\mathrm{w}$ fazie nie REM, zawiera on liniowe związki pomiędzy procesami homeostazy i całodobowymi oraz wykładniczą składową inercyjną opisującą zasypianie. W 2003, program komputerowy wykorzystujący model nie miał potrzebnych interfejsów i nie mógłby być aktualizowany w czasie rzeczywistym.

\section{Model prognostyczny sen/czuwanie}

Akerstedt opracował ten model używający empirycznych podmiotowych dane dotyczących czuwania dla zmiennych wzorcowych okresów sen /czuwanie. To znaczy osiem godzin snu, po którym występuje wykładnicza składową budzenia oraz wykładniczej składowej zasypiania. W badaniach wykorzystywano rytm całodobowy z modą czuwania o godzinie 4:48 po południu i wykładniczym inercyjnym okresem zasypiania. Model ten opracowano dla badaczy snu, firm o nieregulowanym czasie i rytmie pracy oraz organizacji opracowujących regulacje prawne $\mathrm{W}$ zakresie

${ }^{5}$ www.dnv.com 
Niezawodność czlowieka $w$ aspekcie bezpieczeństwa....

bezpieczeństwa i higieny pracy. Opracowane oprogramowanie pozwala na uaktualnianie informacji $\mathrm{w}$ czasie rzeczywistym, określanie nie rejestrowanych świadomie okresów snu, oraz określanie krzywych czuwania i zdolności do działania.

\section{System oceny zmęczenia załóg samolotów (SAFE)}

Rozwijał się pierwotnie pod kątem zastosowania w lotnictwie w oparciu o badania laboratoryjne i dane z lotów. Model jest kombinacją sinusoidalnej składowej dziennej i sześciennego trendu liczonego od czasu snu. Aktualnie używany w lotnictwie cywilnym Wielkiej Brytanii przez odpowiednie służby pozwala na określenie parametrów zmęczenia załóg dla dwutygodniowego okresu i prezentację ich w wersji graficznej.

\section{Interaktywny neurobehawioralny model}

W modelu wykorzystano kombinacje składowych całodobowych, homeostatycznych oraz składową inercji zasypiania w celu opracowania neurobechawioralnego modelu zachowania. Jako warunki poczattkowe przyjęto: osiem godziny snu w ciemności i 16 godziny aktywności przy minimalnym oświetleniu 150 luksów. Badania walidacyjne wykonano na ludziach przy zmiennych warunkach oświetleniowych, występowaniu uczucie zmęczenia wywołanego długą podróżą lotniczą i zmianą strefy czasu, braku snu i innym niż 24 godzinny harmonogramem. Oprogramowanie typu PC pozwala na wprowadzanie danych o poziomach oświetlenia i okresach snu oraz czuwania zaś graficzne dane wyjściowe przedstawiają zdolność do działania i minimalną ciepłotę głęboką ciała. Ten model jest używany przez NASA i badaczy DoD.

\section{SAIC Model poznawczy zachowania czlowieka (HPCM)}

Ten holistyczny model uwzględnia zmęczenie jako tylko jednej z czynników stresujących ograniczających możliwości człowieka w przetwarzaniu informacji ( tzn. decyzja - wykonanie, wybór celu, analiza położenia, analiza zadania i komunikacja). HPCM model pozwala na oszacowanie minuta po minucie ludzką efektywność (jako procent od maksimum), czas zwłoki i typ podejmowania decyzji (typy określone przez autorów). Model został zaimplementowany w środowisku Windows wraz $\mathrm{z}$ oprogramowaniem symulacyjnym, którego minutowe estymacje zapisywane są w formacie Excela. HPCM model charakteryzuje się dobrym odwzorowaniem naturalnych zachowań jak podaje Klein. Poza zaburzeniami okresów snu i zmęczeniem w modelu uwzględniono czynniki stresujące takie jak 1) czasu ciśnienie (posiadanie mniej niż optymalnego czasu do wypełnienia zadania), 2) osobowość ( agresywny / ryzyko tolerujący versus. nieagresywny / nielubiący ryzyka), 3) zagrożenie porażką i wzbudzający zaufanie. Model pozwala także na wprowadzanie czynników 
wpływających na stres takich jak trening, doświadczenie, inteligencja i wiedza.

Zakłócenia snu i zmęczenie są głównymi czynnikami stresującymi.

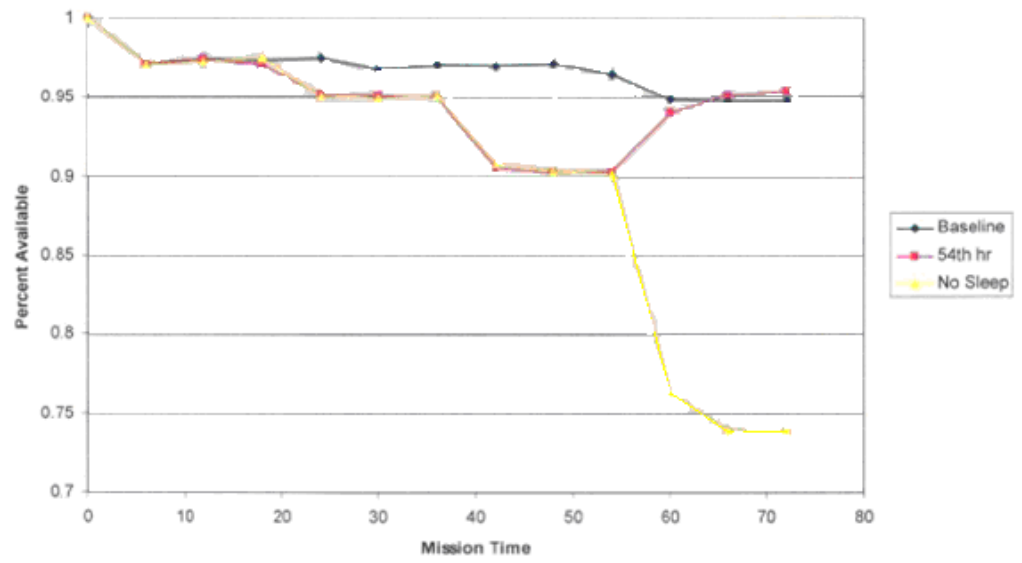

Rys. 3. Zdolność operacyjna w zależności od okresów snu,

Prawdopodobieństwo błędu określone jest wzorem, (2),

$Q\left(\frac{t}{T_{m}}\right)=\exp \left\{-\left(\frac{t-a_{1} \cdot T_{m}}{a_{2} \cdot T_{m}}\right)^{a_{3}}\right\}$

gdzie

- $a_{1}, a_{2}, a_{3}$ parametry zależne wiedzy, doświadczenia, przepisów;

- $\mathrm{T}_{\mathrm{m}}$ średni czas wykonania operacji;

- $t$ czas, jaki człowiek ma na wykonanie operacji.

Model zmęczenia powinien składa się z trzech funkcja :

- pierwszej, która opisuje wpływ koncentracji,

- drugiej, która opisuje spowolnienie czasu wykonania operacji,

- trzeciej, która opisuje wpływ rutyny na pośpiech.

Pierwsze dwie funkcje zależą istotnie od zmęczenia człowieka. Przykład wpływu zmęczenia (nocna wachta) przedstawiony jest $\mathrm{w}$ tabeli na podstawie badań załogi USS John C. Stennis ${ }^{6}$.

Tabela 1. Oszacowanie prawdopodobieństwa przystosowania do zmiany trybu wacht, Gender

\begin{tabular}{|l|r|l|l|}
\hline Pełne przystosowanie & mężczyźni & kobiety & razem \\
\hline nie & 0,409091 & 0,666667 & 0,464286 \\
\hline tak & 0,590909 & 0,333333 & 0,535714 \\
\hline
\end{tabular}

${ }^{6}$ http://www.nps.navy.mil/orfacpag/resumePages/projects/ 
Niezawodność czlowieka $w$ aspekcie bezpieczeństwa ....

\section{Błąd czlowieka i bezpieczeństwo statku}

Operacje na statku podlegają różnym zagrożeniom, zaś bezpieczeństwo $\mathrm{w}$ transporcie morskim oparte jest na zarządzaniu (przepisy), wymaganiach nawigacyjnych, bezpieczeństwie środków technicznych i niezawodności człowieka.

Błędy mogą powstać na skutek ${ }^{7}$ :

- zaniechania

○ opuszczenie procedury, nie podjęcie działań;

- popełnienia

○ wykonanie niepoprawnie operacji, wykonanie operacji zastępczych, wykonanie dodatkowych operacji niezgodnie $\mathrm{z}$ procedura;

- kolejności

○ zła kolejność operacji;

- powtórzenia

○ operacje powtórzone niepotrzebnie

- jakości operacji

○ zbyt wiele lub zbyt mało

- błąd czasu

○ za wcześnie, za późno, za długo.

W każdym z tych przypadków należy także wziąć pod uwagę istotność decyzji podjętej przez człowieka na bezpieczeństwo statku (marynarz w ładowni, sternik na mostku), (3).

Do oceny ryzyka można zastosować model

$P($ accident $)=1-\prod_{k \in K}\left[1-P\left(B D_{k}\right) P\left(I D_{k}\right]^{r_{k}}\right.$

gdzie

$\mathrm{BD}_{\mathrm{k}}$ - błąd wykonania czynności,

$\mathrm{ID}_{\mathrm{k}}$ - istotność błędnej decyzji,

$\mathrm{r}_{\mathrm{k}}$ - ranga błędu $\mathrm{k}$.

$\mathrm{K}$ - zbiór błędów.

Tablica 2. Prawdopodobieństwa awarii na skutek błędu człowieka, na podstawie [4]

\begin{tabular}{|l|l|}
\hline \multicolumn{1}{|c|}{ Typ awarii } & Przedzial ufności 68\% \\
\hline Kolizja statków na kursach przeciwległych & {$\left[1,39 \cdot 10^{-5}: 1,71 \cdot 10^{-4}\right]$} \\
\hline Kolizja statków na kursach przy wyprzedzaniu & {$\left[3,03 \cdot 10^{-5}: 3,92 \cdot 10^{-3}\right]$} \\
\hline Kolizja statków na kursach na kursach przecinających się & {$\left[8,5 \cdot 10^{-5}: 9,82 \cdot 10^{-3}\right]$} \\
\hline Wejście na mieliznę & {$\left[6,07 \cdot 10^{-5}: 4,11 \cdot 10^{-3}\right]$} \\
\hline Zderzenie z obiektem stałym & {$\left[5,16 \cdot 10^{-5}: 6,69 \cdot 10^{-3}\right]$} \\
\hline
\end{tabular}

\footnotetext{
${ }^{7}$ Michael Harrisom, Human error analysis and reliability assessment, DIRC
} 
Tablica 3. Dane osób odpowiedzialnych w wypadku zderzenia Noordam $^{8}$

\begin{tabular}{|c|c|c|}
\hline lokalizacja & funkcja & Systemy informacyjne/kontrolne \\
\hline captain_veniamis & obserwator & arpa_radar \\
\hline pacific_trident & chief oficer & optyczny \\
\hline mount_ymitos & pierwszy oficer & lornetka \\
\hline noordam & trzeci oficer & - \\
\hline- & czwarty oficer & - \\
\hline- & wachtowy oficer & - \\
\hline operatorzy & Speech Acts & zadanie \\
\hline pilot station & inbound_pacific_trident & navigation_radar_check \\
\hline maszynownia & inbound_captain_veniamis & collision_radar_check \\
\hline smit & outbound_mount_ymitos & correlate_radar_targets \\
\hline salyo & curse & declare_end_of_sea_voyage \\
\hline broekhoven & take_bearing_on_lights & fix_vessel_position \\
\hline veldhoen & lights_moving_right & complete_log \\
\hline kuiper & officer_change & notify_engine_room \\
\hline- & - & end_of_sea_voyage \\
\hline- & - & left_full_rudder \\
\hline
\end{tabular}

\section{Wnioski}

Działalność człowieka na morzu stwarza zagrożenia ze względu na znaczący wpływ środowiska na bezpieczeństwo statku, załogi i otoczenia. Poza przepisami, wymogami technicznymi i normami, jakie muszą spełniać statki oraz środkami i systemami ostrzegającymi i zabezpieczającymi także wpływ czynnika ludzkiego musi być brany pod uwagę przy ocenie ryzyka $\mathrm{w}$ transporcie morskim.

Niezawodność człowieka jest jednym z istotnych czynników wpływających na bezpieczeństwo $\mathrm{w}$ transporcie morskim. Występujące ostatnie tendencje do zmniejszania liczebności załóg, będące efektem stosowania nowoczesnych coraz bardziej zautomatyzowanych systemów w siłowniach jak i na pokładzie, moga prowadzić do nadmiernego obciążenie marynarzy zarówno fizycznego jak i psychicznego. Dlatego niezbędnym jest analiza wpływu tych czynników na szanse popełnienia błędu przez człowieka na statku mogącego prowadzić do awarii lub katastrofy.

Ocena niezawodności marynarza $\mathrm{w}$ aspekcie nadmiernego obciążenia jest niezbędnym krokiem do oceny bezpieczeństwa statku.

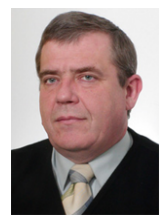

Dr SMOLAREK Leszek, Gdynia Maritime University, Gdynia, Assistant Professor at the Mathematics Department. He has 25 years experience in teaching and research work. He has published more than 30 books, reports and papers in journals and conference proceedings. Specialization: applied mathematics, reliability, statistics, and transport safety.

\footnotetext{
${ }^{8}$ http://www.dcs.gla.ac.uk/research/gaag">Glasgow Accident Analysis Group
} 